\title{
Retina accumulates more glucose than does the embryologically similar cerebral cortex in diabetic rats
}

\author{
J.Tang ${ }^{1}$, X.W.Zhu ${ }^{2}$, W.D. Lust ${ }^{3}$, T.S.Kern ${ }^{1}$ \\ ${ }^{1}$ Center for Diabetes Research and Department of Medicine, Case Western Reserve University, Cleveland, Ohio, USA \\ ${ }^{2}$ Department of Pathology, Case Western Reserve University, Cleveland, Ohio, USA \\ ${ }^{3}$ Department of Neuroscience, Case Western Reserve University, Cleveland, Ohio, USA
}

\section{Abstract}

Aims/hypothesis. The retina is embryologically similar to cerebral cortex and the tissues of both are exposed to similar blood glucose concentrations. Nevertheless, in diabetes the retina develops metabolic abnormalities and microvascular lesions from which cerebrum seems relatively protected. We directly compared glucose concentrations and expression of GLUT-1 (the major carrier transporting glucose from blood into the neural retina and cerebrum) in the two tissues from normal and diabetic rats.

Methods. Tissue and intracellular glucose were measured using two methods: direct assay of glucose and assay of Amadori products on intracellular proteins. The expression of GLUT-1 was measured using western blots in tissue and in the isolated endothelial luminal membrane of the two vascular beds.

Results. Both methods assessing intracellular glucose indicate that intracellular concentrations of glucose in diabetes increased significantly in the retina but not in cerebral cortex. Concentrations of free glucose and Amadori product in retinas of diabetic animals were increased above normal by $334 \%$ and $122 \%$, re- spectively, whereas there was no statistically significant increase in either parameter in the cerebral cortex of diabetic animals. In contrast to the observed increase in glucose in the retina in diabetes, expression of GLUT-1 on the luminal plasmalemma of the retinal vascular endothelium and in homogenates of whole retina decreased to a statistically significant extent $(55 \%$ and $36 \%$, respectively compared to normal). In the luminal cell membrane of the cerebral vasculature, diabetes did not decrease expression of GLUT-1 but tended to increase it slightly.

Conclusions/interpretation. Even among tissues that do not require insulin for glucose uptake, tissue glucose concentration varies in diabetes. The greater increase in glucose concentration in retina than in cerebrum in diabetes probably contributes to the tissue differences in biochemical and histopathologic sequelae of the disease. The expression of GLUT-1 in the microvasculature is unlikely to account for the differences in tissue glucose between retina and cerebrum. [Diabetologia (2000) 43: 1417-1423]

Keywords Diabetic retinopathy, hyperglycaemia, Amadori product, glucose transporter, brain, retina.
Experimental evidence strongly implicates hyperglycaemia in the pathogenesis of diabetic retinopathy.

Received: 3 April 2000 and in revised form: 21 July 2000

Corresponding author: T.S. Kern, $\mathrm{PhD}$, Clinical and Molecular Endocrinology, Department of Medicine, 434 Biomedical Research Building, Case Western Reserve University, 10800 Euclid Ave., Cleveland, OH 44106-4951, USA

Abbreviations: MES, (Morpholino)ethanesulphonic acid; $\mathrm{RPE}$, retinal pigment epithelium; Na,K ATPase, sodium potassium ATPase; PKC, protein kinase C.
Non-diabetic animals in which blood hexose concentration has been increased by feeding a diet enriched with galactose develop a retinopathy that is morphologically identical to capillary lesions which develop in experimentally diabetic animals [1]. Consistent with a role of hyperglycaemia in the development of the retinopathy are studies showing that intensive insulin therapy sufficient to correct or minimize hyperglycaemia inhibits the development of retinopathy [2-4]. The mechanism by which hyperglycaemia causes diabetic retinopathy is, however, not clear. 
Retina and cerebral cortex are embryologically similar, yet have been found by us [5] and others [6, 7] to differ in their susceptibility to develop microvascular lesions in diabetes. The frequency of acellular capillaries, microaneurysms and pericyte loss becomes statistically significantly greater than normal in retinal capillaries of diabetic or galactosaemic animals. Cerebral capillaries, in contrast, fail to develop these lesions, even in the same animals that have developed statistically significant retinovascular disease [5]. Inasmuch as both retinal and cerebral vascular beds are exposed to similar concentrations of blood hexose, these observations suggest that systemic blood glucose concentration is not the only factor influencing the development of retinal vascular disease in diabetes.

Most of the biochemical mechanisms that have been postulated to contribute in the pathogenesis of diabetic retinopathy (including increased activities of aldose reductase or protein kinase $\mathrm{C}$ (PKC), and aspects of non-enzymatic glycation or oxidative stress) depend on excessive transport or accumulation of glucose within the retina or its microvasculature. Transport of hexose into cells can vary between cell types and such differences might be important in determining which cells are adversely effected by hyperglycaemia. The initial step in delivery of glucose to the retina or brain is its transport across the microvascular endothelium by the GLUT-1 glucose transporter [8].

Tissue glucose has been measured previously in the retina $[9,10]$ or brain [11-13] of diabetic animals but glucose concentrations of the two embryologically similar tissues have not been directly compared. In our study, effects of diabetes on intracellular concentrations of glucose in retina and cerebral cortex are compared. The effect of diabetes on expression of GLUT-1, the major glucose transporter in the vasculature of the retina and brain, on the luminal surface of the vascular beds also is compared between the two tissues.

\section{Materials and methods}

Male Sprague-Dawley rats weighing 225-250 g were assigned at random to become diabetic or to remain as non-diabetic controls. Diabetes was induced by the injection of freshly prepared solution of streptozotocin in citrate buffer $(\mathrm{pH} \mathrm{4.5)}$ at $55 \mathrm{mg} / \mathrm{kg}$ of body weight in the tail vein. We measured 24-h urine volume (over 2-3 consecutive days) beginning about 1 week after the streptozotocin injection to confirm the development of diabetes and again after 6 to 8 weeks of diabetes. Body weight and average daily food consumption were measured weekly. Treatment of animals conformed to the American National Institutes of Health "Principals of laboratory animal care", Association for Research in Vision and Ophthalmology (ARVO) Resolution on Treatment of Animals in Research, as well as to specific institutional guidelines.

Tissue concentrations of glucose were estimated by two methods. The first was a direct measure of tissue glucose con- centrations using enzyme cycling (quantitative histochemistry) micromethods. Intracellular concentrations of hexose were estimated also using an indirect method based on the extent of Amadori product formation on intracellular proteins. Nonenzymatic glycation and formation of Amadori products are greatly stimulated by increased sugar concentrations in diabetes $[14,15]$.

Direct assay of tissue glucose. Retinas and cerebral cortex of anaesthetized normal $(n=10)$ or diabetic ( 2 month; $n=10)$ rats were frozen in situ by the funnel freezing method [16]. This method freezes tissues with liquid nitrogen while blood continues to be oxygenated and circulate through the tissues. Funnel freezing has been found to be a good method to collect neural tissues for assay of glucose and other metabolites without artefactual loss $[16,17]$. Animals were maintained on a respirator throughout the freezing process and blood gases and $\mathrm{pH}$ remained normal. After the head was frozen, cryosections of eye and cerebral cortex grey matter were cut $(20 \mu \mathrm{m})$ and lyophilized. Microsamples of neural retina (including all layers; collected from posterior retina) and cerebral cortex grey matter were dissected from the lyophilized tissue under a stereozoom microscope with transillumination. Samples were weighed with a quartz fishpole balance (average dry weight $=1.5 \mu \mathrm{g}$ ) and tissue glucose assayed using the enzyme cycling techniques (quantitative histochemistry) described originally by Lowry and Passonneau and later used by Lust and others [17]. The first step involves incubation of the tissue sample with hexokinase, glucose-6-phosphate dehydrogenase, NADP and excess concentrations of ATP to stoichiometrically generate NADPH from glucose. The reaction is terminated in $0.2 \mathrm{~N} \mathrm{NaOH}$ at $80^{\circ} \mathrm{C}$ which also destroys all the excess NADP. The NADPH is amplified by enzymic cycling and one of the cycling products is determined fluorometrically with the appropriate enzyme reaction. The lower level of sensitivity of the assay is less than 0.1 pmol. Metabolite concentrations are reported as nmol per mg dry tissue weight.

Non-enzymatic glycation of intracellular protein. Amadori products (due to non-enzymation glycation) on intracellular protein were measured as an indirect estimate of intracellular glucose concentration, because glucose is a major glycating agent in cells (especially in diabetes). Tissues from normal and diabetic ( 2 month) animals (both $n=8$ ) were sonicated in buffer $(10 \mathrm{mmol} / \mathrm{l}$ TRIS containing $0.5 \mathrm{mmol} / \mathrm{l}$ EGTA and $0.25 \mathrm{~mol} / \mathrm{l}$ sucrose; $\mathrm{pH} 7.4)$ and centrifuged at high speed (120000 $\mathrm{g}$ for $60 \mathrm{~min}$ ) to remove proteins other than those in the cytoplasmic fraction. The supernatant containing these cytoplasmic proteins was applied to commercially available affinity columns containing $m$-phenylboronic acid (Glyco-Gel; Pierce, Rockford, Ill., USA), which retain proteins that have been non-enzymatically glycated. Chromatography was done according to the manufacturer's instructions. Protein content of the bound and unbound fractions was measured [18] and the per cent of cytoplasmic protein that was glycated was calculated.

Measurement of GLUT-1. The expression of GLUT-1 was measured in homogenates of retina and in isolated luminal membranes of the retinal and cerebral vasculatures of seven non-diabetic rats and seven rats that had been diabetic for 2 months. Tissues were homogenized in $10 \mathrm{mmol} / \mathrm{l}$ TRIS containing $0.5 \mathrm{mmol} / 1$ EGTA and $0.25 \mathrm{~mol} / \mathrm{l}$ sucrose ( $\mathrm{pH} 7.4$ ). Protein $(10 \mu \mathrm{g}$ of retinal homogenate and $2 \mu \mathrm{g}$ luminal membrane stripped from vascular endothelium) were loaded per lane and electrophoresed as described previously [19]. Protein was measured using BCA reagent (Pierce). Primary antibody 
(anti-GLUT-1; 1/1000 dilution) was obtained from Charles River Pharmaservices (Southbridge, Mass., USA). After SDS-PAGE and transfer to nitrocellulose membrane, blots were incubated in $5 \%$ non-fat milk and then incubated for $1 \mathrm{~h}$ with primary antibody and peroxidase-labelled goat anti-rabbit IgG. Blots were developed using an enhanced chemiluminescence kit (Amersham Life Science; Amersham, England). Films were digitized and the intensity of bands was quantitated using OS-Scan Image Analysis software (USB State Biochemical, Cleveland, Ohio, USA). To show comparable loading of lanes, some membranes were cut in two, with the portion corresponding to molecular weight greater than about $70000 \mathrm{M}_{\mathrm{r}}$ stained with antibody against the intrinsic membrane protein, $\mathrm{Na}, \mathrm{K}$ ATPase ( $\alpha 1$ subunit; University of Iowa Hybridoma facility, USA) and the portion corresponding to lower molecular weights stained with anti-GLUT-1.

Isolation of the luminal surface of the retinal and cerebral vasculatures. The luminal plasmalemma of the endothelium as well as attached plasmalemma vesicles was isolated from 18 normal rats and 16 diabetic rats by perfusing in situ with buffer to remove blood, followed by a cationized silica to bind to the luminal surface of the vascular endothelium and then anionic polyacrylate [20-22]. The result is a particulate coat on the endothelium that strongly adheres to the luminal plasmalemma, resists tissue homogenization, thereby allowing purification of the luminal plasmalemma. Methods have been detailed elsewhere [20,23] but are summarized here. A cannula was placed in the ascending aorta of anaesthetized rats such that perfusate entered both carotids. Animals were injected with nitroprusside (vasodilator) and heparin and then the head perfused sequentially with DMEM/nitroprusside (to remove blood), (morpholino)ethanesulphonic acid (MES)-buffered saline, colloidal silica, MES-buffered saline, $1.5 \%$ sodium polyacrylate in MES-buffered saline and HEPES-buffered sucrose $(\mathrm{pH}$ 7.2) containing protease inhibitors (o-phenanthroline, phenylmethylsulphonyl fluoride, leupeptin, pepstatin A and trans-epoxysuccinyl-L-leucyamido(4-guanidino)butane). After perfusion, both retinas or cerebral cortex grey matter were homogenized in the aforementioned solution containing freshly prepared protease inhibitors and the homogenate centrifuged $(20 \mathrm{~min}$ at $60000 \times \mathrm{g})$ in a Nycodenz discontinuous density gradient $(1.02 \mathrm{~g} / \mathrm{ml}$ and $0.7 \mathrm{~g} / \mathrm{ml}$ of Nycodenz in $25 \mathrm{mmol} / \mathrm{l} \mathrm{HEPES}$ containing $60 \mathrm{mmol} / \mathrm{l}$ sucrose) to yield a homogeneous pellet of luminal plasmalemma fragments adherent to silica particles. The membrane fragments were dissolved off the insoluble beads with $50 \mathrm{mmol} / \mathrm{l}$ HEPES buffer ( $\mathrm{pH} 7.4)$ containing $150 \mathrm{mmol} / 1 \mathrm{NaCl}, 5 \mathrm{mmol} / \mathrm{l}$ each of EDTA and EGTA, $20 \mathrm{mmol} / 1$ sodium pyrophosphate, $1 \mathrm{mmol} / \mathrm{l}$ orthovanadate, $20 \mathrm{mmol} / \mathrm{l}$ sodium fluoride and $1 \%$ Nonide P-40 (detergent). Samples were prepared for western blots by solubilizing in SDS sample buffer. The total amount of protein isolated in the endothelial luminal plasmalemma from both retinas per animal was about 50-60 $\mu \mathrm{g}$.

Statistical analysis. The data are summarized with the means \pm SD. The normal and diabetic groups were compared with the parametric t-test. The nom-parametric Mann-Whitney $U$ test yielded similar conclusions. Groups were regarded as significantly different at a $p$ value less than 0.05 .

\section{Results}

Diabetic animals were insulin-deficient, as evidenced by increased concentrations of non-fasting blood glu-

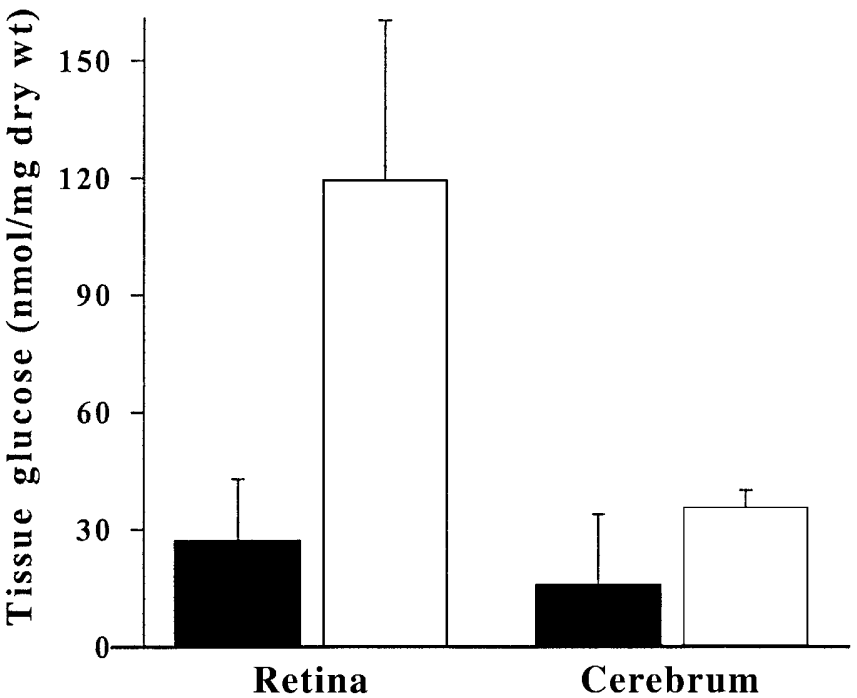

Fig. 1. Glucose concentration is increased more by diabetes in the retina than it is in cerebral cortex grey matter of the same animals. $\square=$ normal, $\square=$ diabetes

cose (non-diabetic, $8.1 \mathrm{mmol} / 1 \pm 0.6$; diabetic, $19.2 \pm$ 2.9 ) and 24-h urine volume (non-diabetic, $8 \mathrm{mls} /$ day \pm 2 ; diabetic, $132 \pm 27)$. Body weight $(490 \pm 116 \mathrm{~g}$ and $272 \pm 58 \mathrm{~g}$ ) was significantly less in diabetic than in normal animals.

Direct measure of tissue glucose by quantitative histochemistry indicates that free glucose concentration in the retina of diabetic animals was increased fourfold above that seen in non-diabetic animals (Fig. 1; $p<0.001$ ). In contrast, glucose content of the cerebral cortex from the same diabetic animals was not significantly increased $(p=0.5)$. Retinas and brains were collected from the same animals, so both tissues were exposed to the same blood glucose concentrations. Expressing glucose concentration in retina and cerebrum relative to that in blood from the same animals indicates that cerebral glucose concentration increased in proportion to the rise in blood glucose. In both non-diabetic animals and diabetic animals, the ratio of glucose in cerebrum to that in blood,

$\underline{\text { (nmol glucose in cerebrum } / \mathrm{mg} \text { cerebral protein) }}$

(nmol glucose in blood/ $\mu$ l blood)

remained constant at 1.9. In contrast, diabetes increased the glucose concentration in retina almost twofold greater than the increase in blood glucose concentration (ratio of glucose in retina to glucose in blood $=3.4$ and 6.2 for non-diabetic and diabetic, respectively). Even in non-diabetic animals, the free glucose concentration in the retina was greater than in cerebral grey matter.

Non-enzymatically glycated proteins (Amadori products) in cytoplasm of the retina and cerebral cortex grey matter of non-diabetic and diabetic rats also were quantified as an independent estimate of intra- 


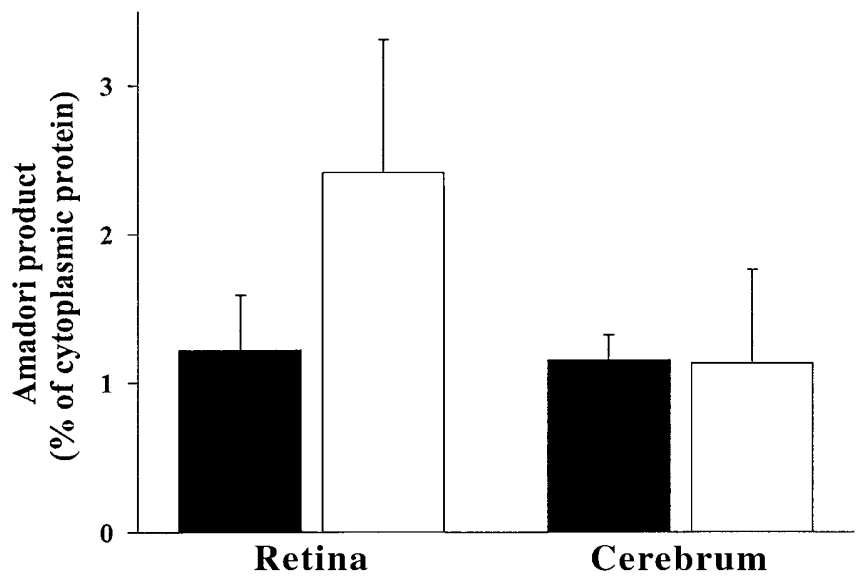

Fig. 2. Diabetes of 2 months duration results in greater accumulation of Amadori products on intracellular proteins in the retina than in the cerebral cortex. Per cent of protein retained by affinity column (Amadori product) is expressed relative to total protein applied to the column. $\square=$ normal, $\square=$ diabetes

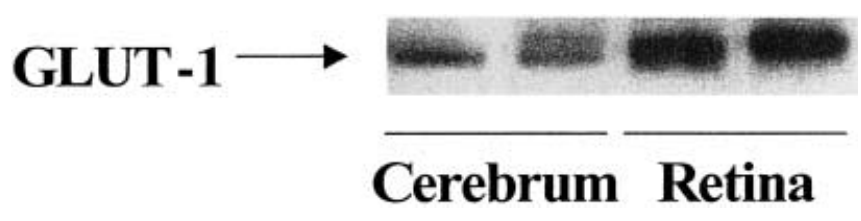

Fig.3. There is more expression of GLUT-1 in the luminal plasmalemma of the retinal vasculature than of the cerebral vasculature in non-diabetic rats

cellular hexose concentrations. Diabetes of 2 months duration caused no increase in glycation of intracellular proteins in cerebral cortex $(p=0.96$ compared with normal) but caused a statistically significant increase in glycation of cytoplasmic proteins of the retina in the same animals (Fig. $2 ; p=0.01$ compared with normal).

The luminal cell membrane of the retinal and cerebral vasculatures (the sites at which glucose is transferred from blood into tissue) had different amounts of GLUT-1 in non-diabetic animals, the luminal surface of retinal endothelial cells possessing considerably more GLUT-1 than did the cerebral vasculature (Fig.3). Diabetes decreased expression of the glucose transporter on the luminal surface of the retinal vasculature to a value only $45 \%$ of that observed in normal animals ( $p<0.0001 ;$ Fig. 4$)$. Consistent with this, diabetes caused a decrease in GLUT-1 expression also in homogenates of whole retina (36\% decrease compared with normal; $p<0.013$; not shown). Expression of the glucose transporter in the luminal surface of the cerebral vasculature was not decreased in diabetes; the cerebral vasculature of diabetic animals tended to have more GLUT-1 protein ( $22 \%$ more) than found in the luminal plasmalemma of cerebral vessels from non-diabetic animals (not significant; $p=0.11$; Fig. 5).
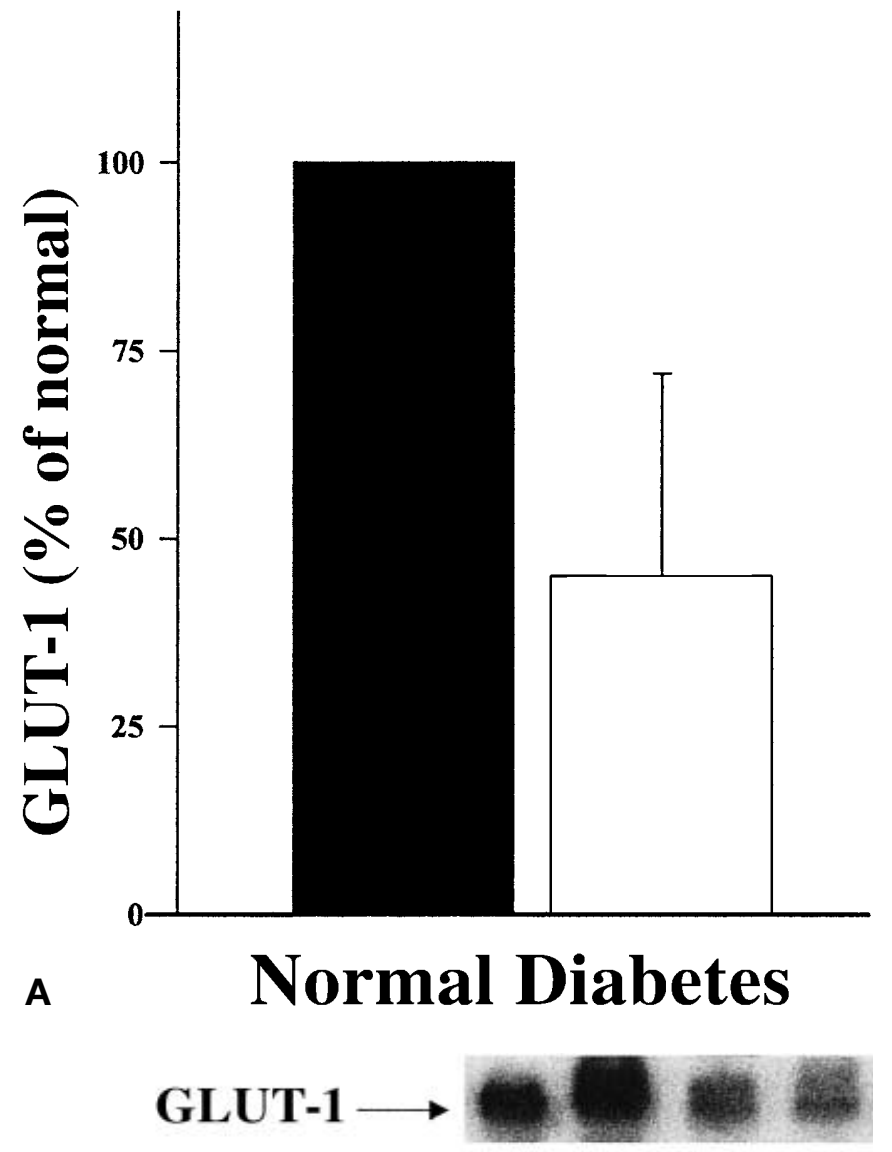

$\mathrm{Na}, \mathrm{K}$ ATPase $\longrightarrow$

B

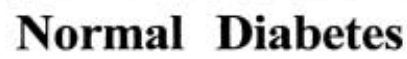

Fig. 4 A, B. Diabetes decreased expression of GLUT-1 in luminal membranes of retinal blood vessels, whether expressed relative to the amount in normal controls on the same western blot (A) or to the amount of intrinsic membrane protein, $\mathrm{Na}, \mathrm{K}$ ATPase $(\mathbf{B})$ in the luminal membranes

\section{Discussion}

Data from two different methods suggest that diabetes increases intracellular concentrations of glucose significantly more in the retina than in cerebral cortex. The two different methods used to estimate tissue glucose complement each other. For example, measurement of Amadori products of intracellular proteins yields a variable that has the advantages of being less labile than free glucose, and focuses primarily on the intracellular environment. Amadori products, however, might not occur solely from glucose, and measurement of tissue glucose clearly addresses this issue.

Increased concentrations of intracellular glucose in the retina of diabetic animals is not surprising, having been suggested by PKC activation, oxidative stress and polyol formation in retinas of diabetic animals [24-30]. The brain however, responds different- 


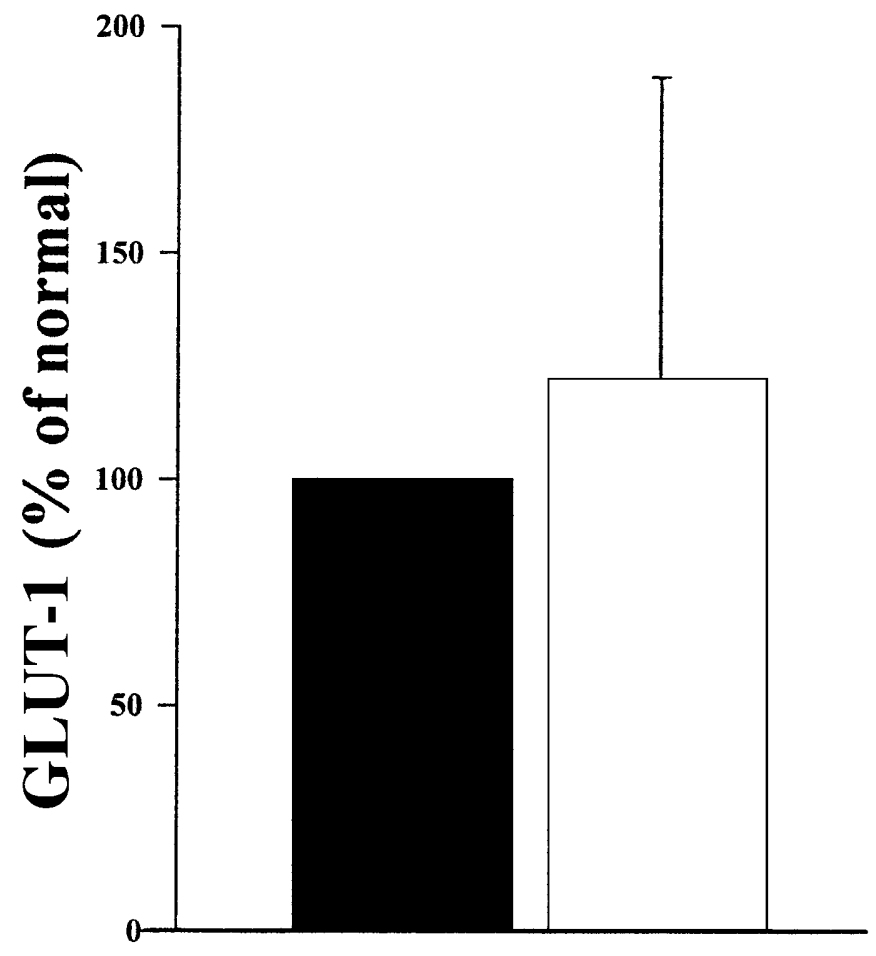

A

\section{Normal Diabetes}

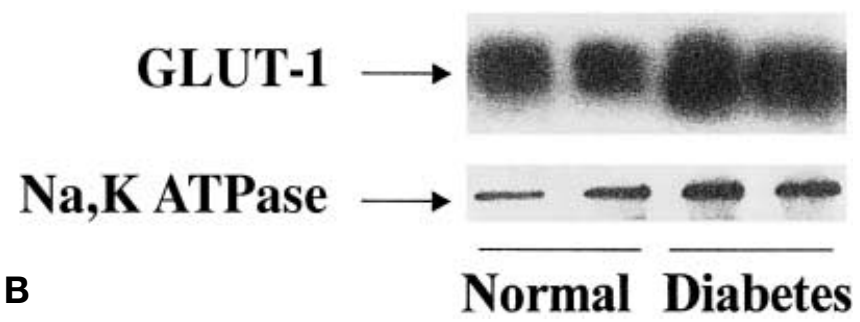

Fig.5 A, B. Diabetes did not decrease expression of GLUT-1 in luminal membrane of the cerebral vasculature, whether expressed relative to the average amount of GLUT-1 expressed in normal controls on the same western blot $(\mathbf{A})$ or to the amount of $\mathrm{Na}, \mathrm{K}$ ATPase (B)

ly to systemic hyperglycaemia than does the retina, showing little or no accumulation of reactive oxygen species or sorbitol or activation of PKC [13, 29-33]. The different biochemical responses of these two tissues to hyperglycaemia might be due to different amounts of PKC, aldose reductase or enzymes in the production or metabolism of reactive oxygen species but data we present suggests that differences in intracellular accumulation of glucose also might be important. Diabetes has been reported to cause some increase in intracellular glucose concentration in cerebral cortex [11-13] but non-invasive measurement of glucose in the intact brain of humans using ${ }^{13} \mathrm{C}$ NMR spectroscopy indicates that the tissue is relatively protected from hyperglycaemia, brain glucose concentrations being only $3 \mathrm{mmol} / \mathrm{l}$ when plasma glucose is more than $12 \mathrm{mmol} / \mathrm{l}$ [34].
The cause of this diabetes-induced tissue difference in glucose accumulation is not clear. Glucose concentration within cells reflects a balance between movement of the sugar into and out of cells and the intracellular rate of glucose metabolism. Whether or not diabetes has different effects on the rate of glucose metabolism in the retina and cerebrum of diabetic animals is not clear. There is, however, more GLUT-1 (in capillaries and retinal pigment epithelium) delivering glucose to neural retina than there is for cerebral cortex grey matter [35], raising a possibility that relatively more glucose is delivered to retina than to cerebral cortex grey matter. Reportedly GLUT-1 accounts for all glucose transport from blood into the brain (and presumably retina) [8]. In our hands, GLUT-1 expression in retinal homogenates and in intact isolated retinal microvessels of diabetic rats was subnormal [35], not increased as might have been inferred from the observed increase in tissue glucose concentration in the retina of diabetic animals. Consistent with this, GLUT-1 now is shown by us to be decreased also on the luminal surface of the retinal vasculature, the surface at which glucose is moved into the endothelium from blood. The luminal surface of cerebral capillaries from the same animals showed no such reduction in GLUT-1 expression in diabetes. The different response of GLUT-1 in the cerebrum and retina to the same increase in blood glucose remains to be explained. In another study, normal or increased numbers of GLUT-1 transporters in capillaries of three diabetic patients were observed, and thus the opposite conclusion about the effect of diabetes on GLUT-1 density in retinal capillaries was reached [36]. The reason for the different conclusions is not clear but that study differed from ours in subjects (humans vs rats), the duration of diabetes (years vs 2 months) and the methods used to detect GLUT-1 (ultrastructural immunohistochemisty vs immunochemical analysis of tissue homogenates and isolated vessels).

Glucose enters the retina from blood also across the retinal pigment epithelium (RPE) and appreciable GLUT-1 has been observed in those cells [35, 37-39]. In contrast to the diabetes-induced decrease in expression of GLUT-1 in retinal capillaries, we previously found that diabetes causes no reduction in GLUT-1 expression in RPE cells [35]. This data suggests that the increase observed in retinal glucose in diabetes might be due in part to transport across the RPE.

Vascular permeability has been found to be increased in the retina in diabetes, whereas the brain shows little or no permeability defect [40-43], offering a potential mechanism for glucose entry into neural retina that is independent of glucose transporters. The difference in vulnerability of the barriers in the two tissues has been suggested to be due to differences in the tissue surrounding the vessels [43]. The dia- 
betes-induced increase in retinal permeability reportedly can be normalized using pharmacological agents, including aldose reductase inhibitors [44, 45]. This observation suggests that the retinal glucose concentration is increased before the permeability defect develops, because the kinetics of aldose reductase indicates that increased activity of the enzyme is a result of increased intracellular hexose concentrations. Increased retinal permeability clearly can exacerbate glucose accumulation in diabetes, but the extent to which it initiates glucose accumulation in the retina is not clear.

Although the recognized histopathology of diabetic retinopathy involves the microvasculature, it seems unlikely that the diabetes-induced increase in glucose concentration observed by us in the retina is restricted only to vascular cells. The vasculature is only a minor fraction of tissue, so the doubling of glucose in the retina of diabetic animals suggests that glucose is increased also in non-vascular cells. Others have postulated a role of glia or neuronal abnormalities in the pathogenesis of diabetic retinopathy [46].

Histological studies have shown that the microvasculature of the cerebral cortex is relatively protected from the diabetes-induced microvascular disease that develops in retinal microvessels [5-7]. It seems likely that the relative protection of the cerebral microvasculature from diabetes-induced microvascular disease is due in part to lesser accumulation of glucose in cerebral cortex than in the retina. Identification of how retinal glucose concentration becomes disproportionately increased in diabetes and how glucose accumulation is minimized in cerebral cortex, might offer a new perspective on ways to inhibit the development of diabetic retinopathy.

Acknowledgements. This study was supported in part by the Medical Research Service of the Department of Veteran Affairs and by the National Institutes of Health No. EY003000 (both to T.S. Kern). Support from the core facilities of the Case Western Reserve University Visual Sciences Research Center (P30EY11373) is also acknowledged. Dr. J. Tang is a recipient of a fellowship from Lions Club International Sightfirst program administered by the American Diabetes Association. We sincerely appreciate the skillful technical assistance of C. Miller.

\section{References}

1. Engerman RL, Kern TS (1984) Experimental galactosemia produces diabetic-like retinopathy. Diabetes 33: 97-100

2. Diabetes Control and Complications Trial Research Group (1993) The effect of intensive treatment of diabetes on the development of long-term complications in insulin-dependent diabetes mellitus. N Engl J Med 329: 977-986

3. Engerman RL, Bloodworth JM Jr, Nelson S (1977) Relationship of microvascular disease in diabetes to metabolic control. Diabetes 26: 760-769

4. United Kingdom Prospective Diabetes Study (1998) Intensive blood-glucose control with sulphonylureas or insulin compared with conventional treatment and risk of complications in patients with type 2 diabetes. Lancet 352: 837-853

5. Kern TS, Engerman RL (1996) Capillary lesions develop in retina rather than cerebral cortex in diabetes and experimental galactosemia. Arch Ophthalmol 114: 306-310

6. de Oliveira F (1966) Pericytes in diabetic retinopathy. Br J Ophthalmol 50: 134-143

7. Addison DJ, Garner A, Ashton N (1970) Degeneration of intramural pericytes in diabetic retinopathy. BMJ 1: 264-266

8. Pardridge WM, Boado RJ, Farrell CR (1990) Brain-type glucose transporter (Glut-1) is selectively localized to the blood-brain border. J Biol Chem 26: 18035-18040

9. Poulsom R, Mirrlees DJ, Earl DC, Heath H (1983) The effects of an aldose reductase inhibitor upon the sorbitol pathway, fructose-1-phosphate and lactate in the retina and nerve of streptozotocin-diabetic rats. Exp Eye Res 36: 751-760

10. Heath H, Kang SS, Philippou D (1975) Glucose, glucose-6phosphate, lactate and pyruvate content of the retina, blood and liver of streptozotocin-diabetic rats fed sucroseor starch-rich diets. Diabetologia 11: 57-62

11. Stewart MA, Sherman WR, Kurien MM, Moonsammy GI, Wisgerhof M (1967) Polyol accumulations in nervous tissue of rats with experimental diabetes and galactosaemia. J Neurochem 14: 1057-1066

12. Mans AM, DeJoseph MR, Davis DW, Hawkins RA (1988) Brain energy metabolism in streptozotocin-diabetes. Biochem J 249: 57-62

13. Knudsen GM, Jakobsen J, Barry DI, Compton AM, Tomlinson DR (1989) Myo-inositol normalizes decreased sodium permeability of the blood-brain barrier in streptozotocin diabetes. Neuroscience 29: 773-777

14. Baynes JW, Watkins NG, Fisher CI et al. (1989) The Amadori product on protein: structure and reactions. Prog Clin Biol Res 304: 43-67

15. Brownlee M (1992) Glycation products and the pathogenesis of diabetic complications. Diabetes Care 15: 1835-1843

16. Lust WD, Ricci AJ, Selman WR, Ratcheson RA (1989) Methods of fixation of nervous tissue for use in the study of cerebral enerby metabolism. In: Boulton AA, Baker GB, Butterworth RF (eds) Carbohydrates and energy metabolism. Neuromethods vol II. Humana Press, Clifton, New Jersey pp 1-41

17. LaManna JC, Hachiu MA, Kutina-Nelson KL et al. (1996) Decreased energy metabolism in brain stem during central respiratory depression in response to hypoxia. J Appl Physiol 81: 1772-1777

18. Bradford MM (1974) A rapid and sensitive method for the quantitation of microgram quantities of protein. Anal Biochem 72: 248-258

19. Badr GA, Zhang J-Z, Tang J, Kern TS, Ismail-Beigi F (1999) Glut1 and Glut3 expression, but not capillary density, is increased by cobalt chloride in rat cerebrum and retina. Brain Res Mol Brain Res 64: 24-33

20. Jacobson BS, Schnitzer JE, McCaffery M, Palade GE (1992) Isolation and partial characterization of the luminal plasmalemma of microvascular endothelium from rat lungs. Eur J Cell Biol 58: 296-306

21. Schnitzer JE, Oh P, Jacobson B S, Dvorak AM (1995) Caveolae from luminal plasmalemma of rat lung endothelium: microdomains enriched in caveolin, $\mathrm{Ca}(2+)$-ATPase, and inositol trisphosphate receptor. Proc Natl Acad Sci USA 92: 1759-1763

22. Beaulieum E, Demeule M, Ghitescu L, Beliveau R (1997) $\mathrm{P}-$ Glycoprotein is strongly expressed in the luminal mem- 
branes of the endothelium of blood vessels in the brain. Biochem J 326: 539-544

23. Jacobson BS, Stolz DB, Schnitzer JE (1996) Identification of endothelial cell-surface proteins as targets for diagnosis and treatment of disease. Nat Med 282-484

24. Kern TS, Engerman RL (1991) Retinal polyol and myoinositol in galactosemic dogs given an aldose reductase inhibitor. Invest Ophthalmol Vis Sci 32: 3175-3177

25. Shiba T, Inoguchi T, Sportsman JR, Heath WF, Bursell S, King GL (1993) Correlation of diacylglycerol and protein kinase $\mathrm{C}$ in rat retina to retinal circulation. Am J Physiol 265: E783-E793

26. Kern TS, Engerman RL (1995) Galactose-induced retinal microangiopathy in rats. Invest Ophthalmol Vis Sci 36: 490-496

27. King GL, Kunisaki M, Nishio Y, Inoguchi T, Shiba T, Xia P (1996) Biochemical and molecular mechanisms in the development of diabetic vascular complications. Diabetes 55 [Suppl 3]: S105-S108

28. Kowluru RA, Kern TS, Engerman RL, Armstrong D (1996) Abnormalities of retinal metabolism in diabetes or experimental galactosemia. III. Effects of antioxidants. Diabetes 45: 1233-1237

29. Kowluru RA, Kern TS, Engerman RL (1996) Abnormalities of retinal metabolism in diabetes or experimental galactosemia. IV. Antioxidant defense system. Free Radicals Biol Med 22: 587-592

30. Kowluru RA, Jirousek MR, Stramm LE, Farid NA, Engerman RL, Kern TS (1998) Abnormalities of retinal metabolism in diabetes or experimental galactosemia. V. Relationship between protein kinase $\mathrm{C}$ and ATPases. Diabetes 47: 464-469

31. Kowluru R, Kern TS, Engerman RL (1994) Abnormalities of retinal metabolism in diabetes or galactosemia II. Comparison of gamma-glutamyl transpeptidase in retina and cerebral cortex, and effects of antioxidant therapy. Curr Eye Res 13: 891-896

32. Tilton RG, Chang K, Nyengaard JR, Van den Enden M, Ido Y, Williamson JR (1995) Inhibition of sorbitol dehydrogenase. Effects on vascular and neural dysfunction in streptozocin-induced diabetic rats. Diabetes 44: 234-242

33. Kowluru RA, Engerman RL, Kern TS (1999) Effects of aminoguanidine on hyperglycaemia-induced retinal metabolic abnormalities. Diabetes 48 [Suppl 1]: A19 (Abstract)

34. Gruetter R, Novotny EJ, Boulware SD et al. (1992) Direct measurement of brain glucose concentration in humans by ${ }^{13} \mathrm{C}$ NMR spectroscopy. Proc Natl Acad Sci USA 89: 1109-1112

35. Badr GA, Tang J, Ismail-Beigi F, Kern TS (2000) Diabetes down-regulates Glut1 expression in retina and its microvessels, but not in cerebral cortex or its microvessels. Diabetes 49: 1016-1021

36. Kumagai AK, Vinores SA, Pardridge WM (1996) Pathological upregulation of inner blood-retinal barrier GLUT1 glucose transporter expression in diabetes mellitus. Brain Res 706: 313-317

37. Tornquist P, Alm A (1979) Retinal and choroidal contribution to retinal metabolism in vivo. A study in pigs. Acta Physiol Scand 106: 351-357

38. Takata K, Kasahara T, Kasahara M, Ezaki O, Hirano H (1992) Ultracytochemical localization of the erythrocyte/ HepG2-type glucose transporter (GLUT1) in cells of the blood-retinal barrier in the rat. Invest Ophthalmol Vis Sci 33: 377-383

39. Kumagai AK, Glasgow BJ, Pardridge WM (1994) GLUT1 glucose transporter expression in the diabetic and nondiabetic human eye. Invest Ophthalmol Vis Sci 35: 2887-2894

40. Pugliese G, Tilton RG, Speedy A et al. (1990) Vascular filtration function in galactose-fed versus diabetic rats: The role of polyol pathway activity. Metabolism 39: 690-697

41. Pugliese G, Tilton RG, Chang K et al. (1990) Effects of islet isografts on hemodynamic and vascular filtratration changes in diabetic rats. Diabetes 39: 323-332

42. Vinores SA, McGehee R, Lee A, Gadegbeku C, Campochiaro PA (1990) Ultrastructural localization of blood-retinal barrier breakdown in diabetic and galactosemic rats. J Histochem Cytochem 38: 1341-1352

43. Mooradian AD (1997) Central nervous system complications of diabetes mellitus - a perspective from the bloodbrain barrier. Brain Res Brain Res Rev 23: 210-218

44. Tilton RG, Chang K, Pugliese G et al. (1989) Prevention of hemodynamic and vascular albumin filtration changes in diabetic rats by aldose reductase inhibitors. Diabetes 37 : $1258-1270$

45. Tilton RG, Pugliese G, LaRose LS et al. (1991) Discordant effects of the aldose reductase inhibitor sorbinil an vascular structure and function in chronically diabetic and galactosemic rats. J Diabetes Complications 5: 230-237

46. Barber AJ, Lieth E, Khin SA, Antonetti DA, Buchanan AG, Gardner TW (1998) Neural apoptosis in the retina during experimental and human diabetes. Early onset and effect of insulin. J Clin Invest 102: 783-791 